\title{
Reliability analysis for structure of Airborne Air Conditioner
}

\author{
Yin Sai Guo ${ }^{1, a^{*}}$, Yi Zhang ${ }^{1, b}$, Wei Wu $^{1}$, Ming Ke Cheng ${ }^{1}$ \\ ${ }^{1}$ Department of graduate, Xijing University, Xi'an710123, China; \\ a $^{*}$ guoysxj@163.com, bhangyjd@163.com,
}

Key words: Airborne Air Conditioner; Reliability analysis; Fatigue life; Stochastic finite element.

\begin{abstract}
As the airborne air conditioner suffers from the variance of nature of the material, structure features, loads applied and stochastic factors, the fatigue life of its structure tends to deviate from the designed life. Based on stochastic finite element method, a mathematic model of the reliability analysis of fatigue life is established about the structure size, damage, fatigue parameters and load. The reliability analysis of fatigue life problem is transformed into the double objective problems of mean and standard deviation of fatigue life, which is balanced through the power factor. The reliability of fatigue life is improved by adopting this method.
\end{abstract}

\section{Introduction}

Since the 1970 s TAGUCHI proposed the three design method to reduce the influence of uncertain factors on the quality, reliability design has been applied in many fields [1] [2]. Due to the random factors such as material properties, geometrical characteristic of structural member, load history and environmental condition, the fatigue life of structure often deviates from the design life of the airborne air conditioner. Based on the stochastic finite element method, reliability optimization model of the fatigue life of the structure is established about the structure size, damage, fatigue parameters and load. The reliability of fatigue life is improved effectively by adopting the method $[3]$.

\section{Structural Fatigue Lifetime}

By the method of $\mathrm{S}-\mathrm{N}$, when a stress ratio $\mathrm{R}$ is given, the fatigue life of structure can be expressed [4]:

$$
N S_{\max }^{m}=C
$$

In the formula, $S_{\max }$-Maximum stress, $\mathrm{N}$ - the cycles of structure destroyed under the effect of maximum stress $S_{\max }, \mathrm{M}$ and $\mathrm{C}$ as structure material fatigue parameters. As the smaller variability of material parameter $\mathrm{m}, \mathrm{m}$ is taken as a certain value. Currently most of the existing material fatigue parameters are obtained in the case of $\mathrm{R}=1$, so formula (1) is turned into:

$N S_{-1}^{m}=C$

If the effect of mean stress is considered, based on Goodman formula, there is:

$S_{-1}=\frac{S_{a}}{1-S_{m} / S_{b}}$

In the formula, $S_{b}$-Strength limit, $S_{a}$-Stress amplitude, $S_{m}$-Stress average 


$$
\begin{gathered}
S_{a}=\frac{S_{\max }-S_{\min }}{2} \\
S_{m}=\frac{S_{\max }+S_{\min }}{2}
\end{gathered}
$$

$\mathrm{S}_{\max }$ - Maximum stress, $\mathrm{S}_{\min }$ - Minimum stress.

Based on the formula (2)and (3), there is:

$$
N=C\left(\frac{S_{b}}{S_{b}-S_{m}}\right)^{-m}
$$

The structure under random load, based on the Miner rule, the cumulative damage of the structure:

$$
D=\sum_{i=1}^{k} \frac{n_{i}}{N_{i}}=\frac{1}{C} \sum_{i=1}^{k} n_{i}\left(\frac{S_{b}}{S_{b}-S_{m}} S_{a_{i}}\right)^{m}=\frac{1}{C} \sum_{i=1}^{k} n_{i} S_{e_{i}}^{m}
$$

In the formula, k-Series of stress amplitude level, $S_{e_{i}}^{m}$-the equivalent stress under the level of stress amplitude level i.

$S_{e_{i}}^{m}=\frac{S_{b}}{S_{b}-S_{m_{i}}} S_{a_{i}}$

Structure is damaged under the level of $\mathrm{D}=\Delta$, the fatigue life $\mathrm{T}_{\mathrm{f}}$ of structure life:

$$
T_{f}=\frac{\Delta}{D}=\frac{\Delta C}{\sum_{i=1}^{k} n_{i} S_{e_{i}}^{m}}
$$

\section{Stochastic Finite Element Method}

Linear elastic finite element equation [5] [6]:

$$
K U=F
$$

In the formula, K- The total stiffness matrix, U- The displacement matrix, F- The load matrix of the equivalent node.

According to the stress-strain relationship:

$S=D B U$

In the formula, S- The stress, D- The elastic stress and strain matrix, B- The deformation matrix.

From equation (10):

$$
E(S)=D B E(U)
$$

The first order Taylor expansion of displacement $\mathrm{U}$ at the average random variable $\mathrm{X}$ is carried out:

$$
\begin{aligned}
& E(U) \approx \bar{U}=\bar{k}^{-1} \bar{F} \\
& \sigma^{2}(U) \approx \sum_{i=1}^{n} \sum_{j=1}^{n} \frac{\partial U}{\partial x_{i}} \frac{\partial U}{\partial x_{i}} \operatorname{Cov}\left(x_{i}, x_{j}\right), x=\bar{x}
\end{aligned}
$$

In the formula, $\bar{U}$ - The value of displacement $\mathrm{U}$ on $\bar{X}, \bar{k}$ - The value of The total stiffness matrix $\mathrm{K}$ on $\bar{X}, \bar{F}$ - The value of The load matrix $\mathrm{F}$ on $\bar{X}, \operatorname{Cov}\left(\mathrm{x}_{\mathrm{i}}, \mathrm{x}_{\mathrm{j}}\right)$ - The covariance of random 
variable $\mathrm{x}_{\mathrm{i}}, \mathrm{x}_{\mathrm{j}}$.

Stress variance can be obtained from the type:

$$
\begin{aligned}
& \sigma^{2}(S) \approx \sum_{i=1}^{n} \sum_{j=1}^{n} \frac{\partial S}{\partial x_{i}} \frac{\partial S}{\partial x_{i}} \operatorname{Cov}\left(x_{i}, x_{j}\right) \\
& \frac{\partial S}{\partial x_{i}}=\frac{\partial D}{\partial x_{i}} B U+D B \frac{\partial U}{\partial x_{i}}
\end{aligned}
$$

Take the derivative of $\mathrm{x}$ on both sides of (10):

$$
\frac{\partial U}{\partial x_{i}}=k^{-1}\left(\frac{\partial F}{\partial x_{i}}-\frac{\partial k}{\partial x_{i}} U\right)
$$

\section{The Mathematical Model for Optimization Problems of the Reliability of Structure Fatigue Life}

The mathematical model for optimization problems of the deterministic structural:

find $\mathrm{d}$

$\min f(d)$

$$
\begin{array}{ll}
\text { s.t } \quad g_{i}(d) \leq 0 \quad(\mathrm{i}=1,2, \ldots, \mathrm{k}) \\
d^{L} \leq d \leq d^{U}
\end{array}
$$

In the formula, $f(d)$ - Objective function, $g_{i}(d)$ - constraint function, $d^{L}-$ The lower limit of design variables, $\mathrm{d}^{\mathrm{U}}$ - The upper limit of design variables, $\mathrm{d} € \mathrm{R}$.

The design variables and random variables of the structure will appear variation, which affects the fatigue life of the system structure [7] [8]. The sensitivity of the variation is decreased through the study of the reliability of the system structure. The reliability problem is transformed into the double objective optimization problem of mean and standard deviation of structure fatigue life. The robustness of structure fatigue life is improved by changing the weight factor of mean and standard deviation of the fatigue life. Standard deviation and expectations of the structure performance function are brought in the objective function and constraint conditions. The mathematical model of optimization design of structure fatigue life reliability:

find $\mathrm{d}$

$$
\begin{aligned}
& \min f(d)=(1-\alpha)\left[E(Z(d))-\ln T_{0}\right]^{2}+\alpha \sigma^{2}(Z(d)) \\
& \text { s.t. } \ln T_{L} \leq E(Z(d))-n \sigma(Z(d)) \\
& E(Z(d))+n \sigma(Z(d)) \leq \ln T_{U} \\
& E\left(g_{i}(d)\right)+n \sigma\left(g_{i}(d)\right) \leq 0 \quad(\mathrm{i}=1,2, \ldots, \mathrm{m}) \\
& d^{L} \leq d \leq d^{U} \\
& \ln T_{0}=\left(\ln T_{L}+\ln T_{U}\right) / 2
\end{aligned}
$$

In the formula, $\mathrm{T}_{\mathrm{L}^{-}}$The lowest design life, $\mathrm{T}_{\mathrm{U}^{-}}$The highest design life, $\mathrm{T}_{0^{-}}$Expectation life; $\alpha$-The weight factor, as the value of the weight factor is different, the reliability of different structure fatigue life is different; n-It is determined by the feasibility probability, and the greater its value is, the better the reliability of fatigue life is; $Z(d)$ - The function of structure fatigue life: 


$$
\begin{aligned}
& Z(d)=\ln T_{f}=\ln \square+\ln C-\ln \left(\sum_{i=1}^{k} n_{i} S_{e_{i}}^{m}\right) \\
& S_{a}=\frac{S_{\mathrm{m} \mathrm{a} \mathrm{x}}-S_{\mathrm{m}}}{2} \\
& S_{m}=\frac{S_{\max }+S_{\min }}{2}
\end{aligned}
$$

By formula (20), (21) and (22),we can know :

$$
\begin{aligned}
& E(Z(d))=E(\ln \square)+E(\ln C)-\ln \left(\sum_{i=1}^{k} n_{i} S_{e_{i}}^{m}\right) \\
& \sigma^{2}(Z(d))=\sigma^{2}(\ln \square)+\sigma^{2}(\ln C)=-\sum_{i=1}^{k}\left[\left(\frac{\partial Z}{\partial S_{e_{i}}} \frac{\partial S_{e_{i}}}{\partial S_{\text {max }_{i}}}\right)^{2} \sigma^{2}\left(S_{\text {max }_{i}}\right)+\left(\frac{\partial Z}{\partial S_{e_{i}}} \frac{\partial S_{e_{i}}}{\partial S_{\text {min }_{i}}}\right)^{2} \sigma^{2}\left(S_{\text {min }_{i}}\right)\right]
\end{aligned}
$$

In the formula (24), $\sigma^{2}\left(S_{\text {max }_{i}}\right), \sigma^{2}\left(S_{\text {min }_{i}}\right)$ can be got by using the method of stochastic finite element.

\section{Reliability Analysis for Structure of Airborne Air Conditioner}

The airborne air conditioner structure is shown in figure 1. The Al7075 is chose as the structure material. Its density is $2810 \mathrm{~kg} / \mathrm{m} 3$. Its yield strength is $455 \mathrm{Mpa}$. As the safety coefficient is 1.3 . Its elasticity modulus is $71700 \mathrm{Mpa}$ and poisson's ratio is 0.33 . Design variables are the cross section area of the structure. The variation coefficient of the cross section area is 0.1 . The rest of the random variables are shown in table 1 . The Minimum design life $T_{L}$ is $10^{6}$, and the highest design life $T_{U}$ is $10^{9}$.The constraint functions of the structure:

$g=E\left(\left|S_{i}\right|\right)+2 \sigma\left(S_{i}\right) \leq 360,(i=1,2, \ldots, 8$,

In the formula (25), $\mathrm{S}_{\mathrm{i}}$ - The stress of rod $\mathrm{i}$.

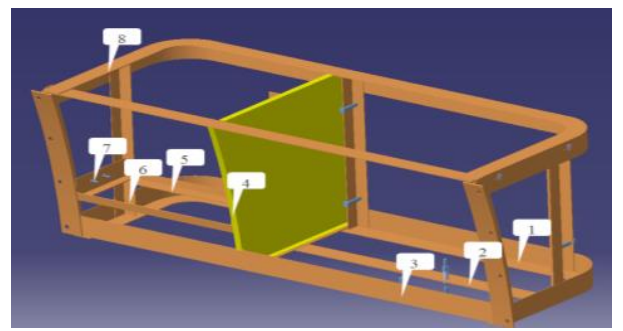

Fig. 1 Airborne evaporation circulatory system structure

The study results were got when the weight factor was $0,0.5,1.0$, which is shown in table 2 . As can be seen from the results, the greater the $\alpha$ is, the greater the different value of the structure life and the expected logarithmic life $\mathrm{E}\left(\ln \mathrm{T}_{0}\right)=16.258$ is; The smaller the logarithmic $\sigma\left(\ln \mathrm{T}_{\mathrm{f}}\right)$ of structure fatigue life is, the smaller the variation range of structure life is. Conversely, the smaller the $\alpha$ is, the smaller the different value of the structure life and the expected logarithmic life $\mathrm{E}\left(\ln \mathrm{T}_{0}\right)$ is; The greater the logarithmic $\sigma\left(\ln _{\mathrm{f}}\right)$ of structure fatigue life is, the greater the variation range of structure life is. So reasonable weight factor $\alpha$ is chose to improve the reliability of fatigue life of airborne evaporation circulatory system structure. 
Table 1 Random variables of 8 structures

\begin{tabular}{cccc}
\hline Random variable & Mean value & Standard deviation & Distribution pattern \\
\hline Damage $\Delta$ & 1 & 0.12 & Lognormal distribution \\
Fatigue parameters C & $6.56 \mathrm{e} 30$ & $6.56 \mathrm{e} 30$ & Lognormal distribution \\
Load $\mathrm{p}_{1} / \mathrm{MPa}$ & $1.4 \mathrm{e}-002$ & $1.4 \mathrm{e}-003$ & Lognormal distribution \\
Load $\mathrm{p}_{2} / \mathrm{MPa}$ & $1.3 \mathrm{e}-003$ & $1.3 \mathrm{e}-004$ & Gaussian distribution \\
Load $\mathrm{p}_{3} / \mathrm{MPa}$ & $1.8 \mathrm{e}-002$ & $1.8 \mathrm{e}-004$ & Gaussian distribution
\end{tabular}

Table2 Optimization results of 8 structures

\begin{tabular}{ccccccc}
\hline Design variable & $\begin{array}{c}\text { lower } \\
\text { limit }\end{array}$ & $\begin{array}{c}\text { upper } \\
\text { limit }\end{array}$ & $\begin{array}{c}\text { original } \\
\text { value }\end{array}$ & $\alpha=0$ & $\alpha=0.5$ & $\alpha=1$ \\
\hline AreaA1/m & 0.0045 & 0.010 & 0.008 & $\begin{array}{c}0.0082 \\
16\end{array}$ & 0.009125 & 0.009672 \\
$\begin{array}{c}\text { Logarithmic average } \\
\text { lifeE }\left(\ln \mathrm{T}_{\mathrm{f}}\right) / \text { frequency }\end{array}$ & 14.365 & 21.526 & 17.581 & 16.258 & 18.216 & 20.516 \\
$\begin{array}{c}\text { Logarithmic life standard } \\
\text { deviation } \sigma\left(\ln \mathrm{T}_{\mathrm{f}}\right) / \text { frequency }\end{array}$ & - & - & 0.7014 & 0.5812 & 0.4959 & 0.4126 \\
\hline
\end{tabular}

\section{Summary}

Based on the stochastic finite element method, the larger dispersion problem of the fatigue life is solved through establishing reliability model of the fatigue life of the airborne air conditioner structure. It provides an efficient and practical new method for the reliability of fatigue life of airborne air conditioner structure.

\section{Acknowledgements}

This study was supported by the Natural Science Foundation of Shaanxi Province (No 2013JM8040), the Scientific Research Program Funded by Shaanxi Provincial Education Department (Program No. 2013JK1204) and Graduate Student Innovation Fund of Xijing University.

\section{References}

[1]An H, An W G, Liu M. Reliability Analysis for Structure System with the Local Dented Plate[J]. Manufacturing Process Technology, 2011.

[2]Bing L, Wei-guang A, Yin-ling C. Reliability Analysis for Ship Spatial Structure Based on SFEM[J]. Journal of Harbin Engineering University, 2002.

[3]Ma C, Lu Z Z. Iterative Algorithm for Structure Reliability Analysis Based on Support Vector Classification Method[J]. Progresses in Fracture \& Strength of Materials \& Structures, 2007.

[4]Yi L, Bin L, Wei C, et al. Handy Method for Reliability Analysis of Frame Structure[J]. Journal of 
Northeastern University, 2002, 23(7):700-702.

[5]Yi-jun T, Yao-zhuang L. The Index Systems Research of Small Town Engineering Structure and Reliability Analysis for Anti-Disaster[J]. Journal of Disaster Pnevention \& Mitigation Engineering, 2005, 25(4):441-445.

[6]Feng Y. Reliability Analysis for Fault-Tolerant Systems of Civil Airborne Systems based on Semi-Markov Model[J]. Equipment Manufacturing Technology, 2011.

[7]Xiao-jie Y, Shao-ping W, Jian S. Computer Assistant Analysis for Reliability of Airborne Electromechanical Systems[J]. Acta Aeronautica Et Astronautica Sinica, 2007, 28(3):708-713.

[8]Jian L. ICE-INDUCED FATIGUE RELIABILITY ANALYSIS FOR STRUCTURE SYSTEM OF OFFSHORE PLATFORMS[J]. Journal of Mechanical Strength, 2005, 27(6):835-839. 